\title{
Hematologic and Chemical Changes Observed during and after C ardiac Arrest in a Canine Model-A Pilot Study
}

\author{
Barry E. Bleske, Pharm.D., Jessica Song, Pharm.D., Moses S. S. Chow, Pharm.D., \\ Jeffrey Kluger, M.D., and C. Michael White, Pharm.D.
}

Study Objective. To evaluate the effect of cardiac arrest and cardiopulmonary resuscitation (CPR) on blood chemistry in a canine model.

Design. Evaluative canine animal study.

Setting. Animal laboratory accredited by the Association for Assessment and Accreditation of Laboratory Animals.

Subjects. Twenty-six adult mongrel dogs.

Intervention. The dogs underwent an episode of induced fibrillatory cardiac arrest for 3 minutes followed by 10 minutes of standard CPR. Blood samples were taken at baseline (before cardiac arrest), after 10 minutes of ventricular fibrillation, and 10 minutes after successful resuscitation for determination of blood chemistries and hematologic parameters.

Measurements and Main Results. Glucose, blood urea nitrogen, serum creatinine, sodium, potassium, chloride, calcium, phosphorus, uric acid, alkaline phosphatase, lactate dehydrogenase, aspartate aminotransferase, alanine aminotransferase, protein, albumin, cholesterol, triglycerides, iron, white blood cell count, red blood cell count, and hematocrit were measured. Significant changes $(p<0.05)$ in values obtained during CPR versus baseline values were noted for all laboratory parameters except blood urea nitrogen, chloride, and alkaline phosphatase. Eighteen dogs achieved return of spontaneous circulation (ROSC); their laboratory values were obtained after CPR. Significant changes $(\mathrm{p}<0.05)$ after ROSC compared with baseline were noted for all laboratory values except chloride, blood urea nitrogen, uric acid, alkaline phosphatase, glucose, potassium, calcium, triglycerides, iron, red blood cell count, and hematocrit.

Conclusion. Results indicate that significant changes in blood chemistries and hematologic parameters occur during and after CPR. Clinicians should note these normal laboratory parameter changes when interpreting laboratory data in patients who experience cardiac arrest.

(Pharmacotherapy 2001;21(10):1187-1191)

Cardiac arrest results in cessation of circulation, and cardiopulmonary resuscitation (CPR) only partially restores circulation of blood. Hence, compromised blood circulation persists until return of spontaneous circulation (ROSC) is achieved. ${ }^{1}$

Acute alterations to circulation of blood-from no flow (at the time of cardiac arrest) to partial flow (during CPR), and finally to ROSC - can alter acid-base and biochemical parameters. ${ }^{1-3}$ However, these effects on overall blood chemistry and hematologic parameters are not well described. Previous studies have either evaluated a limited number of biochemical parameters ${ }^{4}$ or examined overall blood chemistry at time points considerably beyond the acute CPR phase. ${ }^{5}$ 
Without an appreciation of normal chemical and hematologic derangements that occur during and after cardiac arrest, researchers and health care providers cannot adequately evaluate laboratory data in an animal study involving drugs that may alter electrolyte or hematologic parameters, or in an individual patient with cardiac arrest.

Since animal cardiac arrest models are well established and often used to evaluate potential interventions in cardiac arrest, we evaluated the effect of cardiac arrest with CPR after ROSC on laboratory parameters in dogs. To our knowledge, no study has evaluated alterations in overall blood chemistry and hematologic parameters during CPR.

\section{Methods}

Laboratory data for 26 adult mongrel dogs (weight $12-16 \mathrm{~kg}$ ) were collected from two separate studies of cardiac arrest and CPR. Use of these dogs was approved by the Animal Care Institutional Review Committee of Hartford Hospital, Hartford, Connecticut, and the animal laboratory was accredited by the Association for Assessment and Accreditation of Laboratory Animals. In both studies, dogs were anesthetized with thiopental $20 \mathrm{mg} / \mathrm{kg}$ followed by $\alpha$ chloralose $70 \mathrm{mg} / \mathrm{kg}$. They were secured in supine position on a surgical table with a thermoblanket to maintain $37^{\circ} \mathrm{C}$ body temperature. A cuffed endotracheal tube was placed, and the dogs were ventilated by respirator (Harvard volume respirator model 613) at 10 breaths/minute. At baseline, blood gases were stabilized to an arterial blood pH level of $7.40 \pm$ 0.05 and a partial pressure of carbon dioxide level of $40 \pm 5 \mathrm{~mm} \mathrm{Hg}$ with adjustments of tidal volume and/or administration of sodium bicarbonate as required.

Throughout the study, aortic, left ventricular, and right atrial pressures were measured continuously after proper catheterization, and electrocardiogram readings were taken continuously. All animals received heparin 150 $\mathrm{U} / \mathrm{kg}$ periodically to maintain catheter patency.

From the College of Pharmacy, University of Michigan, Ann Arbor, Michigan (Dr. Bleske); the Departments of Pharmacy and Cardiology (Drs. Song and Kluger), and the Drug Information Center (Dr. White), Hartford Hospital, Hartford, Connecticut; the University of Connecticut Schools of Pharmacy and Medicine, Storrs and Farmington, Connecticut (Drs. Song and Kluger); and the Chinese University of Hong Kong, Shatin, Hong Kong (Dr. Chow).

Address reprint requests to C. Michael White, Pharm.D., Drug Information Center, Hartford Hospital, Hartford, CT 06102-5037; e-mail: cmwhite@harthosp.org.
The study involved induction of ventricular fibrillation, CPR, and then defibrillation using the same methods. Ventricular fibrillation was induced with $80 \mathrm{~mA}$ of electrical current through a coronary pacing catheter. After 3 minutes of ventricular fibrillation without ventilation, CPR was performed with a pneumonic chest compression device (Thumper, Michigan Instruments, Grand Rapids, MI) for 10 minutes. The device was set to compress the chest 60 times/minute with a compression duration of 0.5 seconds. Compression force was set to produce an initial coronary perfusion pressure gradient of $20 \mathrm{~mm} \mathrm{Hg}$ and was maintained throughout the CPR period (perfusion pressure gradient was determined by subtracting left-ventricular middiastolic pressure from aortic pressure). After every fifth compression, diastole was prolonged by 0.5 seconds and the lungs were inflated to an inspiratory pressure of approximately $10 \mathrm{~cm}$ of water (with 100\% oxygen) by a synchronized pressure-limited ventilator.

Aortic blood samples were obtained 58 minutes before ventricular fibrillation, after 8-12 minutes of ventricular fibrillation, and at 10 minutes after ROSC. Glucose, blood urea nitrogen $(B U N)$, serum creatinine $\left(S_{c r}\right)$, sodium, potassium, chloride, calcium, phosphorus, uric acid, alkaline phosphatase, lactate dehydrogenase (LDH), aspartate aminotransferase (AST), alanine aminotransferase (ALT), protein, albumin, cholesterol, triglycerides, and iron (American Monitor Parallel Analyzer, American Monitor, New York, NY) were measured. We also obtained white blood cell count, red blood cell count, and hematocrit (H-6000 Auto Analyzer, Technon Instruments, Austin, TX).

\section{Data Analysis}

Laboratory values (expressed as mean \pm SD) at baseline, during CPR, and after ROSC were compared using analysis of variance (ANOVA). If ANOVA demonstrated a significant difference, then the t test with Bonferroni correction was used to determine which group(s) were significantly different. A $\mathrm{p}$ value less than or equal to 0.05 was considered significant.

\section{Results}

Of the 26 dogs undergoing CPR, 18 achieved ROSC. Table 1 shows the laboratory values observed at each stage of our study. Table 2 shows changes during CPR and after ROSC versus baseline values. When ANOVA was used 
Table 1. Laboratory Values Observed at Each Stage of Study (baseline, C PR, ROSC)

\begin{tabular}{|c|c|c|c|c|}
\hline Laboratory Parameter & $\begin{array}{l}\text { Reference } \\
\text { Limit }\end{array}$ & $\begin{array}{l}\text { Baseline } \\
(n=26)\end{array}$ & $\begin{array}{c}\text { During CPR } \\
(n=26)\end{array}$ & $\begin{array}{c}\text { After ROSC } \\
(\mathrm{n}=18)\end{array}$ \\
\hline Glucose (mg/dl) & $75-110$ & $108 \pm 33.8$ & $232 \pm 86.0^{a}$ & $219 \pm 67.2^{\mathrm{a}}$ \\
\hline Blood urea nitrogen $(\mathrm{mg} / \mathrm{dl})$ & $7-25$ & $12.6 \pm 4.2$ & $12.8 \pm 4.8$ & $13.5 \pm 5.5$ \\
\hline Creatinine (mg/dl) & $0.7-1.7$ & $0.84 \pm 0.10$ & $0.93 \pm 0.12^{\mathrm{a}}$ & $1.08 \pm 0.13^{\mathrm{a}, \mathrm{b}}$ \\
\hline Sodium $(\mathrm{mEq} / \mathrm{L})$ & $135-145$ & $148 \pm 3.9$ & $144 \pm 4.1^{\mathrm{a}}$ & $151 \pm 4.0^{\mathrm{a}}$ \\
\hline Potassium $(\mathrm{mEq} / \mathrm{L})$ & $3.2-5.0$ & $3.4 \pm 0.4$ & $4.4 \pm 0.49^{\mathrm{a}}$ & $3.8 \pm 0.53^{\mathrm{a}, \mathrm{b}}$ \\
\hline Chloride (mEq/L) & $97-111$ & $115 \pm 3.1$ & $115.6 \pm 3.2$ & $115.7 \pm 3.1$ \\
\hline Calcium (mg/dl) & $8.8-10.3$ & $9.2 \pm 0.4$ & $8.5 \pm 0.4^{\mathrm{a}}$ & $8.4 \pm 0.4^{\mathrm{a}}$ \\
\hline Phosphorus (mg/dl) & $2.5-4.5$ & $5.1 \pm 0.7$ & $5.7 \pm 0.79^{a}$ & $6.9 \pm 1.1^{\mathrm{a}, \mathrm{b}}$ \\
\hline Uric acid (mg/dl) & $2-9$ & $0.9 \pm 0.3$ & $2.5 \pm 1.1^{\mathrm{a}}$ & $0.6 \pm 0.4$ \\
\hline Alkaline phosphatase (U/L) & $25-100$ & $38.7 \pm 13.2$ & $47.3 \pm 22.6$ & $49.5 \pm 23.1$ \\
\hline Lactate dehydrogenase (U/L) & $100-300$ & $118 \pm 53$ & $184 \pm 94.3^{a}$ & $254 \pm 104.3^{\mathrm{a}, \mathrm{b}}$ \\
\hline Aspartate aminotransferase (U/L) & $5-30$ & $38.3 \pm 12.4$ & $115.7 \pm 28.1^{\mathrm{a}}$ & $223.7 \pm 69.1^{\mathrm{a}, \mathrm{b}}$ \\
\hline Alanine aminotransferase (U/L) & $5-30$ & $28.0 \pm 15.5$ & $101.1 \pm 63.9^{a}$ & $221.8 \pm 129.1^{\mathrm{a}, \mathrm{b}}$ \\
\hline Protein $(\mathrm{g} / \mathrm{dl})$ & $6.3-8.4$ & $4.5 \pm 0.7$ & $3.9 \pm 0.8^{\mathrm{a}}$ & $3.4 \pm 0.8^{\mathrm{a}}$ \\
\hline Albumin (g/L) & $3.7-5.2$ & $2.2 \pm 0.3$ & $1.9 \pm 0.4$ & $1.65 \pm 0.4^{\mathrm{b}}$ \\
\hline Total cholesterol (mg/dl) & $100-245$ & $104 \pm 30$ & $82 \pm 37.1^{\mathrm{a}}$ & $80 \pm 38.2^{a}$ \\
\hline Triglycerides (mg/dl) & $40-180$ & $26 \pm 9.5$ & $45 \pm 26.7^{\mathrm{a}}$ & $26.6 \pm 16.0^{\mathrm{b}}$ \\
\hline Iron $(\mu \mathrm{g} / \mathrm{dl})$ & $60-150$ & $99.9 \pm 30.4$ & $83.0 \pm 39.9$ & $85.2 \pm 40.1$ \\
\hline White blood cell count $\left(\mathrm{x} 10^{3} / \mathrm{mm}^{3}\right)$ & $4.8-10.0$ & $5.3 \pm 3.4$ & $7.3 \pm 4.8$ & $6.9 \pm 5.3$ \\
\hline Red blood cell count (x 10\% $\left./ \mathrm{mm}^{3}\right)$ & $4.6-6.2$ & $5.1 \pm 0.7$ & $6.3 \pm 1.0^{\mathrm{a}}$ & $5.5 \pm 0.8^{b}$ \\
\hline Hematocrit (\%) & $40-54$ & $35.2 \pm 4.5$ & $39.6 \pm 5.1^{\mathrm{a}}$ & $37.7 \pm 5.4$ \\
\hline
\end{tabular}

$\mathrm{CPR}=$ cardiopulmonary resuscitation; $\mathrm{ROSC}=$ return of spontaneous circulation.

${ }^{a}$ Significant difference from baseline $(\mathrm{p}<0.05)$.

${ }^{\mathrm{b} S i g n i f i c a n t}$ difference between $\mathrm{CPR}$ and post-CPR periods $(\mathrm{p}<0.05)$.

Table 2. Changes in Laboratory Parameters during CPR and after ROSC versus Baseline Values

\begin{tabular}{|c|c|c|}
\hline $\begin{array}{l}\text { Laboratory } \\
\text { Parameter }\end{array}$ & $\begin{array}{l}\text { \% Change during CPR } \\
(\mathrm{n}=26)\end{array}$ & $\begin{array}{l}\text { \% Change after ROSC } \\
(\mathrm{n}=18)\end{array}$ \\
\hline Glucose (mg/dl) & $\uparrow 115 \pm 86^{a}$ & $\uparrow 103 \pm 98.7$ \\
\hline Blood urea nitrogen $(\mathrm{mg} / \mathrm{dl})$ & $\uparrow 1.4 \pm 14.0$ & $\uparrow 7.0 \pm 30.0$ \\
\hline Creatinine (mg/dl) & $\uparrow 11.3 \pm 16.9^{a}$ & $\uparrow 29.0 \pm 35.4^{\mathrm{a}}$ \\
\hline Sodium $(\mathrm{mEq} / \mathrm{L})$ & $\downarrow 2.7 \pm 4.4^{\mathrm{a}}$ & $\uparrow 1.8 \pm 4.2^{\mathrm{a}}$ \\
\hline Potassium (mEq/L) & $\uparrow 30.0 \pm 22.0^{\mathrm{a}}$ & $\uparrow 12.3 \pm 32.3^{\mathrm{b}}$ \\
\hline Chloride (mEq/L) & $\uparrow 0.5 \pm 3.8$ & $\uparrow 0.6 \pm 4.0$ \\
\hline Calcium (mg/dl) & $\downarrow 7.6 \pm 6.4^{\mathrm{a}}$ & $\downarrow 8.2 \pm 6.7$ \\
\hline Phosphorus (mg/dl) & $\uparrow 12.5 \pm 13.0^{\mathrm{a}}$ & $\uparrow 35.5 \pm 60.1^{\mathrm{a}}$ \\
\hline Uric acid (mg/dl) & $\uparrow 183 \pm 279^{a}$ & $\downarrow 333 \pm 418$ \\
\hline Alkaline phosphatase (U/L) & $\uparrow 22.1 \pm 71.0$ & $\uparrow 28.0 \pm 75.0$ \\
\hline Lactate dehydrogenase (U/L) & $\uparrow 56.0 \pm 78.0^{\mathrm{a}}$ & $\uparrow 115.0 \pm 96.8^{a, b}$ \\
\hline Aspartate aminotransferase (U/L) & $\uparrow 202 \pm 227^{a}$ & $\uparrow 484 \pm 557^{\mathrm{a}, \mathrm{b}}$ \\
\hline Alanine aminotransferase (U/L) & $\uparrow 261 \pm 312^{\mathrm{a}}$ & $\uparrow 692 \pm 733^{a, b}$ \\
\hline Protein (g/L) & $\downarrow 14.3 \pm 20.0^{\mathrm{a}}$ & $\downarrow 25.2 \pm 20.5^{\mathrm{a}}$ \\
\hline $\operatorname{Albumin}(\mathrm{g} / \mathrm{dl})$ & $\downarrow 15.9 \pm 17.0^{\mathrm{a}}$ & $\downarrow 25.2 \pm 20.9^{\mathrm{a}}$ \\
\hline Total cholesterol (mg/dl) & $\downarrow 16.4 \pm 23.6^{\mathrm{a}}$ & $\downarrow 23.2 \pm 27.4^{\mathrm{a}}$ \\
\hline Triglycerides (mg/dl) & $\uparrow 72.7 \pm 181^{\mathrm{a}}$ & $\uparrow 2.3 \pm 68.6$ \\
\hline Iron $(\mu \mathrm{g} / \mathrm{dl})$ & $\downarrow 16.9 \pm 31.3^{\mathrm{a}}$ & $\downarrow 14.7 \pm 32.0$ \\
\hline White blood cell count $\left(\times 10^{3} / \mathrm{mm}^{3}\right)$ & $\uparrow 37.4 \pm 42.0^{\mathrm{a}}$ & $\uparrow 29.3 \pm 55.7^{\mathrm{a}}$ \\
\hline Red blood cell count (x 10\% $\left./ \mathrm{mm}^{3}\right)$ & $\uparrow 24.3 \pm 48.3^{\mathrm{a}}$ & $\uparrow 6.9 \pm 19.7$ \\
\hline Hematocrit (\%) & $\uparrow 12.6 \pm 14.1^{\mathrm{a}}$ & $\uparrow 7.0 \pm 20.5$ \\
\hline
\end{tabular}

$\mathrm{CPR}=$ cardiopulmonary resuscitation; ROSC $=$ return of spontaneous circulation.

aSignificant difference from baseline $(\mathrm{p}<0.05)$.

bignificant difference between CPR and post-CPR periods ( $\mathrm{p}<0.05)$.

to compare each laboratory parameter for the three stages (baseline, during CPR, and after ROSC), significant differences were found for all except BUN, chloride, alkaline phosphatase, iron, and white blood cell count concentrations. Values for the CPR period differed significantly 
from those at baseline for all laboratory parameters except BUN, chloride, alkaline phosphatase, albumin, total cholesterol, iron, and white blood cell counts. When post-CPR data for the 18 animals that achieved ROSC were compared with baseline values, BUN, chloride, uric acid, alkaline phosphatase, triglyceride, iron, white blood cell count, red blood cell count, and hematocrit levels were not significantly different. Hence uric acid, triglyceride, red blood cell count, and hematocrit levels changed significantly during CPR from baseline values, but changes that occurred in the post-CPR period lost significance compared with baseline values. Conversely, albumin and total cholesterol levels did not change significantly during CPR but changed significantly after ROSC. Compared with laboratory parameters obtained during CPR, potassium, triglycerides, red blood cell count, and hematocrit levels were significantly lower after ROSC, whereas liver transaminases ( $\mathrm{LDH}$, AST, ALT), creatinine, and phosphorus were significantly higher after ROSC.

\section{Discussion}

Significant changes for most chemical and hematologic parameters occur during cardiac arrest with CPR compared with baseline values. Similarly, changes induced during CPR are generally maintained 10 minutes after ROSC for most parameters.

Potassium levels after ROSC were significantly lower than during CPR. The potassium increase during cardiac arrest and CPR may be due to an extracellular shift of potassium by ventricular fibrillation-induced acidosis. Similarly, after ROSC, acidosis theoretically would be abolished and potassium would again shift intracellularly. This initial increase in potassium during CPR followed by a decrease toward normal after successful ROSC has been described. ${ }^{6}$ In addition, serum potassium increased from $3.7 \pm$ $0.3 \mathrm{mEq} / \mathrm{L}$ at baseline to $3.9 \pm 0.6 \mathrm{mEq} / \mathrm{L} 5$ minutes after resuscitation in a study of cardiac arrest in 30 adult mongrels. ${ }^{4}$ After the transient increase in serum potassium concentration occurred, concentrations decreased below baseline value, achieving a nadir 45-60 minutes after resuscitation. These researchers suggested that endogenous catecholamines could have induced potassium release from the liver or that tissue ischemia and trauma associated with chest massage increased serum potassium concentrations.

Our study showed serum calcium concentrations
0.7 and $0.8 \mathrm{mg} / \mathrm{dl}$ lower than baseline values during CPR and 10 minutes after ROSC, respectively. Likewise, the earlier study ${ }^{4}$ demonstrated serum calcium concentrations 0.7 $\mathrm{mg} / \mathrm{dl}$ lower than baseline values both 5 and 15 minutes after resuscitation. The researchers hypothesized that since endogenous epinephrine activates cellular calcium channels, the decrement in serum calcium may have occurred secondary to increased entry of calcium into cells. However, we also found a reduction in circulating albumin concentrations. Since approximately $80 \%$ of circulating calcium is bound to albumin, and the free calcium level is important in physiologic processes, a correction factor (corrected calcium $=$ measured calcium + 0.8 [normal albumin - actual albumin]) was used. ${ }^{7}$ Using baseline albumin as normal for dogs, we calculated the corrected calcium concentrations during CPR as $8.7 \mathrm{mg} / \mathrm{dl}$ and 10 minutes after ROSC as $8.8 \mathrm{mg} / \mathrm{dl}$, which were still less than the baseline value of $9.2 \mathrm{mg} / \mathrm{dl}$.

In general, reductions in circulating albumin concentrations are due to the combination of three separate effects: extravasation of albumin into the extravascular compartment due to increased capillary permeability to a new equilibrium, downregulation of hepatic albumin synthesis by actions of cytokines (tumor necrosis factor, interleukin-1, and interleukin-6), and increased albumin catabolism. ${ }^{8}$ In this very short time from baseline to cardiac arrest and then ROSC, the only factor that could account for this effect would be a shift of more albumin out of the vasculature and into the extracellular space. This mechanism has been the most rapid means of albumin reduction in patients with other conditions. ${ }^{8}$ Whether it explains the cholesterol reductions observed in our study is not known.

Conversely, results of liver transaminase function tests (LDH, AST, ALT) were significantly higher after than during CPR, although values for both were significantly higher than baseline values. The increase in transaminases after ROSC versus during CPR may represent a washout phenomenon (e.g., liver damage may be occurring primarily during cardiac arrest, but blood flow is insufficient to carry markers for liver injury into general circulation for detection until ROSC is achieved). Impairment of liver blood flow during cardiac arrest and CPR has been demonstrated by our research group and others. ${ }^{9,10}$ This phenomenon would be similar to that seen after thrombolytic or primary angioplasty therapy during acute 
myocardial infarction for creatine kinase MB. ${ }^{11}$

Since the liver stores red blood cells, it may lose some capacity to hold onto this blood component during CPR, which could explain the increase in both red blood cell count and hematocrit. However, the actual reason is not known.

\section{Study Limitations}

Some limitations of data collected in this study must be noted. First, animal models have been used as a surrogate for humans in advanced cardiac life support research and provide information on qualitative rather than quantitative changes that could be expected. Second, our model used a short duration of cardiac arrest and CPR and therefore may not apply to prolonged arrest situations. Third, $\mathrm{pH}$ was not continuously evaluated during the study; if it had been, it may have further elucidated why changes in other substances occurred.

\section{Clinical Implications}

In light of our findings, clinicians should be aware that blood chemistries and hematologic parameters may change in animals and humans during CPR. Alterations of a specific parameter could be due to cardiac arrest, rather than being a cause or precipitant of arrhythmia. For example, if the serum potassium level during CPR is lownormal (3.5-3.7 mEq/L) during cardiac arrest, presence of hypokalemia (a potential contributor) before the arrest cannot be ruled out. Similarly, appreciating that liver transaminases rise after ROSC could be important. Increased AST and ALT levels observed in our study were 3-8 times the upper limit of normal. Administration of intravenous amiodarone during and after cardiac arrest could be valuable but should be stopped if it causes liver toxicity. ${ }^{12}$ However, if increased AST and ALT levels mistakenly are attributed to amiodarone rather than considered a consequence of cardiac arrest with CPR, premature termination of amiodarone could put patients at risk. Furthermore, patients who need other beneficial agents, such as 3-hydroxy- methylglutaryl coenzyme A reductase inhibitors or fibric acid derivatives, may not be given these agents because of perceived (but actually nonexistent) hepatic impairment.

\section{Conclusion}

Several chemical and hematologic parameters change during cardiac arrest with CPR; others change after ROSC. Clinicians need to know which parameters change during and after cardiac arrest when they explore causative factors regarding an arrhythmic event or a potential subsequent problem.

\section{References}

1. Safar P, Bircher N. Cardiopulmonary cerebral resuscitation. In: World federation of societies of anesthesiologists international CPCR guidelines, 3rd ed. Philadelphia: WB Saunders, 1988.

2. Abramson NS, Safar P, Detre K. Factors influencing neurologic recovery after cardiac arrest [abstr]. Brain resuscitation clinical trial II study group. Ann Emerg Med 1989;18:477-8.

3. Cummings RO, ed. Essentials of ACLS. In: Advanced cardiac life support. Baltimore, MD: American Heart Association, 1994.

4. Salerno DM, Elsperger KJ, Helseth P, Murakami M, Chepuri V. Serum potassium, calcium and magnesium after resuscitation from ventricular fibrillation: a canine study. J Am Coll Cardiol 1987;10:178-85.

5. Zwemer CF, O'C onnor EM, Whitesall SE, D'Alecy LG. Gender differences in 24-hour outcome following resuscitation after 9 minutes of cardiac arrest in dogs. Crit Care Med 1997:25:330-8.

6. Martin G B, Carden DL, Nowak RM, et al. Hyperkalemia during cardiac arrest and resuscitation in the canine model. Crit Care Med 1986;14(4):300-2.

7. Ateshkadi A, Pelter MA. Electrolytes, other minerals, and trace elements. In: Traub SL, ed. Basic skills in interpreting laboratory data, 2nd ed. Bethesda, MD: American Society of Health-System Pharmacists 1996:93-130.

8. Sternberg JA, Rohovsky SA, Blackburn GL, Babineau TJ. Total parenteral nutrition for the critically ill patient. In: Grenvik A, ed. Textbook of critical care, 4th ed. Philadelphia: WB Saunders 2000:898-920

9. Barson WG, Levy RC, Weir H. Lidocaine levels during CPR: differences after peripheral venous, central venous, and intracardiac injection. Ann Emerg Med 1981;10:73-8.

10. Chow MSS, Ronfeld RA, Hamilton RA, Helmink R, Fieldman A. Effect of external cardiopulmonary resuscitation on lidocaine pharmacokinetics in dogs. J Pharmacol Exp Ther 1983;224:531-7.

11. American College of Cardiology/American Heart Association Task Force on Practice Guidelines. ACC/AHA guidelines for the management of patients with acute myocardial infarction. J Am Coll Cardiol 1996;28:1328-428.

12. Kudenchuk PJ, Cobb LA, Copass MK, et al. Amiodarone for resuscitation after out-of-hospital cardiac arrest due to ventricular fibrillation. N Engl J Med 1999;341:871-8. 